\title{
So polieren Sie Ihre Praxis auf
}

\author{
Wer als niedergelassener Arzt gut gerüstet in die Zukunft \\ blicken möchte, wird nicht an Marketingmaßnahmen vorbei- \\ kommen, so Marketingspezialist Guido Mecklenbeck. Dabei \\ geht es um mehr als um Praxisbroschüren oder eine eigene \\ Homepage. Wie Sie Ihre Praxis für Ihre Patienten günstiger \\ gestalten und auch besser präsentieren, erfahren Sie im folgen- \\ den Artikel.
}

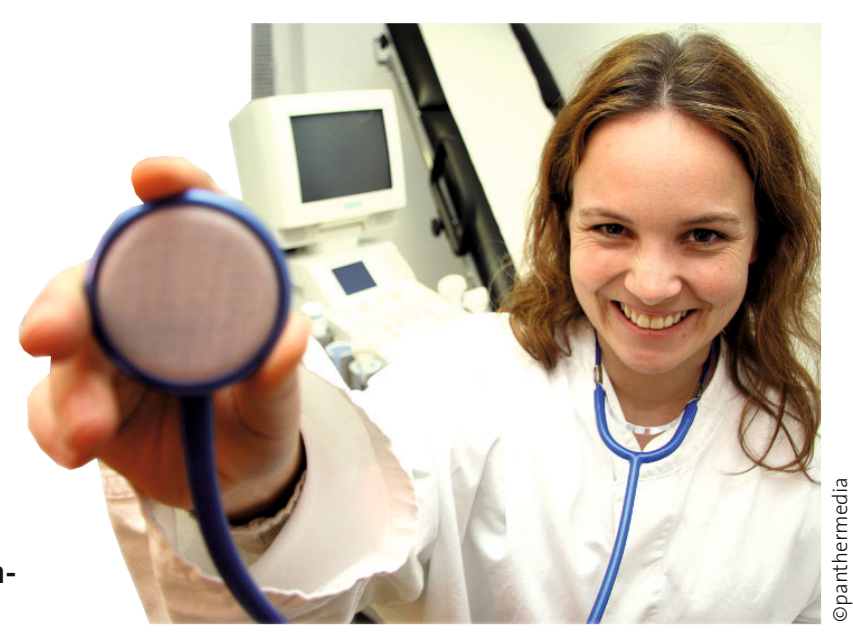

— Nicht selten, so Guido Mecklenbeck von Vendus \& Sales Communication, lassen Ärzte Praxisbroschüren drucken oder investieren Zeit in den Aufbau einer Homepage. Damit zäumen sie das Pferd aber oft von hinten auf. Denn ein zielgerichtetes Praxismarketing beginnt immer mit der Frage: Wo will ich hin? Was ist mein Ziel mit meiner Praxis?

Interessant könnten etwa Kooperationen sein, die beispielsweise das Leistungsspektrum der Praxis sinnvoll ergänzen. Oder man schließt sich gleich einem größeren Netz an, um ein Vertragspartner für die Krankenkassen zu werden.

\section{Patienteninformationen und Recall-Systeme}

Wer sich entlasten bzw. Zeit gewinnen möchte, kann über Maßnahmen nachdenken, wie er die Wartezeit von Patienten für beide Seiten sinnvoll nutzt. Warum etwa soll ein Patient nicht Informationen $\mathrm{zu}$ seiner Krankheit im Wartezimmer zu lesen bekommen, statt gelangweilt in einer Zeitschrift zu blättern? Gleichzeitig wird der Arzt nicht mit Fragen gelöchert, über die sich der Patient bereits während der Wartezeit informiert hat.

Recall-Systeme zu präventiven Maßnahmen werden zwar von den Krankenkassen als auch von den Patienten befürwortet, das Instrument wird aber nur selten genutzt.

\section{Was kann ich verbessern?}

Wichtig, so Mecklenbeck weiter, ist, dass der Arzt kritisch überprüft, wo Verbesserungspotenziale liegen. Was nützt schon ein schicker Hochglanzflyer für IGeL, wenn das Praxispersonal unfreundlich ist, die Wartezimmerstühle unbequem sind und der Teppich verschlissen ist? Schließlich kann ein Patient die „Güte“ eines Arztes kaum an seinem fachlichen Handeln beurteilen. Vielmehr macht er dies an anderen Dingen wie der perfekten Organisation der Praxis oder dem sicheren Auftreten des Teams fest.

Das erste Mittel zur Statusbestimmung der Praxis ist eine selbstkritische Teambesprechung. Noch besser als die Innenbetrachtung ist aber der Blick von außen: Mit einer Patientenbefragung lässt sich eruieren, was gefällt und was stört. Oder fünf bis zehn Per- sonen sollen einfach mal als Probepatienten in die Praxis kommen und berichten, wie es ihnen ergangen ist. Natürlich kann das Team über diesen Testlauf informiert werden, der genaue Zeitpunkt aber sollte nicht unbedingt mitgeteilt werden.

\section{Gewonnene Erkenntnisse umsetzen}

Aus den so gewonnenen Erkenntnissen werden Ziele formuliert. Danach gilt es, Maßnahmen festzulegen und deren Erfolg zu kontrollieren. Kritisieren die Testpatienten etwa Punkte wie „Die Helferinnen waren unfreundlich und hektisch, das Telefon klingelte unentwegt und keiner ging ran“ oder „Es war schwierig, den EKG Raum zu finden", so bieten sich Maßnahmen an wie eine Kommunikationsfortbildung für die Helferinnen, ein Anrufbeantworter für das Rezepttelefon, eine bessere Beschilderung der Praxis etc. Zur Kontrolle wäre dann z.B. ein erneuter Testlauf nach einem Jahr denkbar.

ANKE THOMAS

- Quelle: Online-Vortrag auf www.univadis.de: „1X1 des Praxismarketings“. Referent: Guido Mecklenbeck am 10.02.2010 